\title{
Population Ecology of Whitefly, Bemisia tabaci, (Homoptera: Aleyrodidae) on Brinjal
}

\author{
Mohd Rasdi, Z., Fauziah, I., Fairuz, K., Mohd Saiful, M.S. \& Md Jamaludin, B. \\ Faculty of Applied Science \\ Universiti Teknologi MARA (UiTM) Pahang, 26400, Malaysia
}

Tel: 60-9-460-2467 E-mail: dddpim@pahang.uitm.edu.my

Che Salmah, M.R

School of Biological Sciences, Universiti Sains Malaysia (USM)

11800, Pulau Pinang, Malaysia

Tel: 60-4-653-4061 E-mail: csalmah@usm.my

Kamaruzaman Jusoff (Corresponding author)

Tropical Forest Airborne Observatory (TropAIR)

Faculty of Forestry, Universiti Putra Malaysia

Serdang 43400, selangor, Malaysia

Tel: 60-3-8946-7176 E-mail: kjusoff@yahoo.com

This project is financed by Ministry of Higher Education, Malaysia (PASCA)

\begin{abstract}
Whitefly, Bemisia tabaci (Gennadius), a common insect feeding on plants, belongs to the family Aleyrodidae of the order Homoptera. The quantity of food source especially brinjal, is one of the major factors that has attracted whitefly in the area. In fact, the flight ability of whitefly enables them to search for food quickly. Thus could encourage whitefly to reproduce in great numbers and subsequently cause severe infestation in the fields. Many farmers are not interested to grow brinjal after they have gone through some bad experience due to some whitefly infestations, which have resulted in a total crop loss of brinjal fruits. At present, information on the population dynamics of whiteflies locally on brinjal is still lacking. Henceforth, these studies are indeed appropriate to generate a comprehensive understanding on the insect population, which could support an effective pest management programme and crop improvement strategy. The study was conducted at the Field Laboratory of the Faculty of Applied Science, Universiti Teknologi MARA, Shah Alam. The study on the population of whitefly larvae on brinjal plants covered all the plant strata except for the upper stratum. The populations of whitefly were aggregated (Taylor's Power Law Calculate) in first and second cropping of brinjal plants. It may be concluded that the total number of whitefly larvae were found to be most abundant in the middle stratum of the brinjal plants.
\end{abstract}

Keywords: Whitefly, Bemisia tabaci, Population ecology, Population dynamics

\section{Introduction}

Initial studies showed that the whitefly Bemisia tabaci Gennadius (sweetpotato whitefly) were found in abundance in the lowland areas. This study was carried out to establish the extent which its population and migration would result in colonization of a new habitat by this pest. Furthermore, the economic importance of whitefly is becoming to be a major insect pest especially on brinjal. Brinjal is one of the most popular fruit vegetables grown in Malaysia. Brown and Nelson (1986) reported that Bemisia tabaci has caused problems to the crop as a result of direct feeding damage and indirect 
damage by acting as a vector for several viral plant pathogens such as gemini viruses and clostero viruses (Duffus, 1996). Primarily, this study focused on the population and distribution of whitefly which influenced the development of whitefly in the field. The distribution patterns of whitefly, within and between plants were observed for over two cropping periods. Most estimated populations of whitefly are immature stages which are easier to count. Leaf sampling was carried out to determine the population density and distribution of immature whitefly on brinjal.

\section{Materials and methods}

The field experiment was conducted at the experimental plot of the Plantation Technology and Management Programme, Faculty of Applied Sciences, Universiti Teknologi MARA, Shah Alam, Selangor. The plot consisted of four rows of planting beds, each measuring $10 \mathrm{~m}$ (length) x $1 \mathrm{~m}$ (width) and the distance between beds was $1 \mathrm{~m}$. Each bed was planted with 12 plants of $60 \mathrm{~cm}$ apart between plants. A total of 48 plants were planted in four beds. Two cropping periods of brinjal were observed in the experiment. The first crop began in September 2002 until March 2003 and the second crop commenced from January to May 2003. An overlapped cropping period was planned in order to ensure availability of host plants for continuity of whitefly population. The larvae and pupae of whitefly were monitored through leaf random sampling. Sampling of larvae and pupae commenced two weeks after transplanting as brinjal plants started flushing new leaves. Six leaves were randomly sampled per planting bed. From six leaves, two were taken from each of the following plant strata namely the upper, middle, and lower, representing various stages and distribution of leaves on the plants (Kohji et al., 1993). Leaf samples were kept in plastic bags labelled with bed number and leaf stratum. The leaves were then brought to the laboratory where the larvae and pupae of whitefly were counted under a dissecting microscope. Sampling was carried out weekly until the end of the fruiting stage (13 weeks after transplanting) in both crops.

\section{Data analysis}

Means abundance of weekly whitefly and other insects infesting brinjal were determined and compared between two cropping periods. The data were subjected to one way ANOVA (SAS Programme) (Sandra and Ramon, 1987), and significantly different means $(\mathrm{p}<0.05)$ were separated using Duncan Multiple Range Test (DMRT) at $5 \%$ probability. The data were found normally distributed in both cropping periods (Kolmogorov-Smirnov test (SPSS). Hence, data of means and variances of immature whitefly were $\log _{10} \mathrm{x}$ transformed to normalize the data for analysing spatial distribution. The degree of whitefly aggregation was evaluated based on a simple empirical relationship as $\log \mathrm{s}^{2}=\log \mathrm{a}+\mathrm{b} \log \mathrm{x}$ of Taylor's Power Law Linear Regression (Taylor, 1961 and Taylor, 1984). The slope, b of this regression is a measure of aggregation, random and regular, and the y axis intercept, $a$, is a sampling factor. The value of $b$, which is significantly larger than $1(b>1)$ would indicate aggregation, which is less than one $(b<1)$. It means that the dispersion is uniform while values that are not significantly different from $1(b=1)$ shows a random distribution. Differences in mean abundance of $B$. tabaci during the study period were analysed using ANOVA (one way).

\section{Results and discussion}

Figure 1 shows that total mean larvae (per 6 leaves) of all strata in first cropping was lower than second cropping except at four weeks after transplanting (WAT). In the first cropping the larval population increased to a peak of 39.5 larvae per plant at 4 WAT after which the population decreased drastically at 6 WAT and gradually to very low levels until the end of the study.

\section{$<<$ Figure 1: Distribution and abundance of whitefly larvae on each brinjal plant (total mean larvae in three leaf strata) in two cropping periods. $>>$}

In the second cropping, the population was much higher than the first cropping starting just after transplanting, reaching a high peak of 50 larvae per plant at seven WAT. The population decreased only slightly until the end of cropping. In the first cropping, the distribution of total B. tabaci larvae varied among the three strata of the host plants with the means of 2.13, 5.90, and 9.88 for the upper, middle and lower strata, respectively (Figure 2). In the second cropping, the distribution of mean larvae varied among the three strata of the host crop within the means of 3.52, 24.82, and 11.18 for the upper, middle and lower strata, respectively (Figure 2). The distribution of population means was significantly different in both stratum and cropping period at $\mathrm{p}<0.01(\mathrm{~F}=6.79 ; \mathrm{df}=2,5 ; \mathrm{p}<0.05)$. The distribution of the whitefly larvae was strongly dependent on strata during different cropping periods as the interaction between strata and WAT was different and highly significant. At the upper stratum, the mean number of whitefly larvae was 0.75 at 2 WAT and increased to the highest peak of 4.5 larvae at 3 WAT (Figures 2a). The larval population decreased to 4.25 larvae and drastically to its lowest level (0.5) in 8 WAT. Then, it slightly fluctuated until 13 WAT with 2 larvae on 2 leaves. Initially, the mean number at 2 WAT was 7.0 and started to increase to 10.5 larvae at 3 WAT. The highest mean number of larvae was observed to be 22 larvae at 4 WAT and drastically decreased at 5 WAT. Subsequently, the insect population fluctuated but it did not exceed 5.25 larvae for the following WAT's until the end of first cropping. Figure 2(a) showed that at the lower stratum, initially the number of larvae was slightly increased from 4.751 to 13.25 larvae 2 WAT until 4 WAT, respectively. It reached the highest peak at 5 WAT with 24.25 larvae. Subsequently, the number decreased dramatically with small fluctuation between 6 and 7 WAT, and 10 and 11 WAT. When the larval distributions were investigated at different leaf strata, it was 
found that the pattern of abundance was similar at all three strata for the first cropping. The population drastically increased to the highest peaks at $3 \mathrm{WAT}, 4 \mathrm{WAT}$ and $5 \mathrm{WAT}$ for the upper, middle and lower strata, respectively. The population then decreased gradually and fluctuated slightly in the upper stratum. In the middle and lower strata of brinjal plant, the population decreased drastically to very low level towards the end of the cropping. Generally, more larvae were found in the lower leaf stratum compared with the middle and upper strata. In the second cropping, the distribution of larval population started from the higher levels for the middle and lower strata. Interestingly, more larvae preferred to infest the middle rather than the lower leaves in the first cropping. In the second cropping, the larval population of the middle stratum peaked at 2 WAT at a higher level of 38 larvae per two leaves as compared to the first cropping. However, the larval population was peaked at $3 \mathrm{WAT}$ at the lower leaves with 18 larvae per two leaves.

There was a significant difference $(\mathrm{F}=3.284 ; \mathrm{df}=2,5 ; \mathrm{P}<0.05)$ in the number of whitefly larvae among all the strata in the second cropping period. Whitefly larvae were not observed at the upper stratum of the brinjal plants. However, the number of larvae started to increase until 4 WAT and decreased before it reached the highest peak at 7 WAT. The population decreased until $11 \mathrm{WAT}$ and increased again at the end of cropping period. In the middle stratum [Figures 2(b)], the population of whitefly started to increase in the early cropping period until 6 WAT and then fluctuated between 8 and $10 \mathrm{WAT}$. At the end of second cropping period, the number of whitefly larvae increased again. In the lower stratum, the number of whitefly larvae was found to increase in the early stage of second cropping period [Figure 2(b)]. Then, the population decreased slightly until 7 WAT and increased again at 9 WAT. There was a little fluctuation at the end of the cropping period. The number of whitefly larvae varied on the different strata of brinjal plants, ranging from 0.5 to 4.5 larvae in the upper stratum, 1.75 to 22 larvae in the middle stratum, and 2.75 to 24.25 larvae in the lower stratum. The number of whitefly larvae were higher $(\mathrm{p}<0.05)$ in the lower and middle strata as compared with upper stratum.

The spatial distribution of $B$. tabaci larvae on brinjal plants in the first cropping period was found to be aggregated in all the strata except for the upper stratum (Taylor's Power Law, Figure 3). Results showed that, B. tabaci was uniformly distributed in the upper stratum $(\mathrm{b}=0.51969)$ of the first cropping period. However, the dispersion pattern of $B$. tabaci in the middle and lower strata were found to be significantly different to the upper stratum, where both means showed aggregative pattern of distribution. The middle stratum showed a more obvious aggregated pattern due to the coefficient, $\mathrm{b}$ value being higher than lower stratum. The coefficient values in the first cropping were 1.39825 and 1.04518 for middle and bottom stratum, respectively (Figure 3). The aggregation of B. tabaci larvae in middle and lower strata were due to their large larval number on the under surface of leaves and their immobility. As compared with the upper stratum, possibly the number of larvae emerged on the young leaves was very low. In the second cropping, B. tabaci showed aggregated distribution with the $\mathrm{b}$ values being 1.311, 1.760, and 1.326 for upper, middle and lower strata (Figure 3), respectively. Generally, the populations of whitefly were aggregated for both seasons in all the strata except for the upper stratum in the first cropping.

\section{$<<$ Figure 2: Mean number of whitefly larvae on upper, middle and lower strata of brinjal plant per 2 leaves First cropping (b) Second cropping $>>$}

\section{$<<$ Figure 3: Spatial distribution of whitefly larvae on brinjal with Taylor's Power Law regressions (a) First cropping (b) Second cropping >>}

The distribution of B. tabaci larvae varied among the three-leaf strata of the brinjal plants. This was mainly due to the behaviour of whitefly adults that laid their eggs on the underside of leaves especially on the upper stratum. McAuslane (1995) reported that the eggs were scattered all over the leaf either singly or in cluster. The immature stages lived on the underside of brinjal leaves. The first instar larvae moved some distance around the surface of leaves. They then became sessile and fed on the plant sap until they turned into pupae. Since the shoot of a brinjal plant was the preferential oviposition sites of $B$. tabaci, only adults and eggs were found on the upper stratum of the plant, followed by the first larval instar in the middle stratum, the last larval instar in the lower stratum and lastly the empty pupa on the oldest brinjal leaves. Thus, the major part of the larvae III and larvae IV were concentrated in lower stratum of the plant with leaves of a specific age. By restricting the sampling in this region, efficiency in sampling could be increased. The total number of whitefly larvae of all the strata in the first cropping was lower than that in the second cropping throughout the cropping period (Figure 3). This was because over the duration of the first cropping, the brinjal was planted in a new area. It took a while for the whiteflies to establish their population in this new area. However, in the second cropping, the population flourished immediately after transplanting the crop. The whitefly population from the first cropping immediately moved to the new hosts of brinjal plants in the second cropping which provided a good condition for their oviposition site, shelter and also food sources.

Generally, in both cropping periods, whitefly population started to increase and reached the highest peak during flowering and fruiting stages. The population decreased when the plants reached the end of economic life of four months for brinjal plants. These trends were due to the presence of host plants at initial stage of population growth, and then they reached the highest peak mainly due to availability of food and good shelter. Subsequently, the population started to decrease due to sudden reduction of food and the older leaves became unsuitable for immature whiteflies. In the first cropping, the 
population decreased drastically after $5 \mathrm{WAT}$ as compared to the second cropping. There were many factors affecting the population of whitefly such as climate (temperature, rainfall and relative humidity), natural enemies, surrounding area, and host plants. Horowitz et al. (1984) found that the population dynamic of B. tabaci in cotton fields were mainly due to climatic factors such as humidity and temperature, but parasitism was not a decisive factor. According to Gerling et al. (1986), an extreme relative humidity of both high and low conditions were unfavourable for the survival of immature stages of whitefly. In the second cropping, the immature whiteflies successfully maintained their population until the end of cropping period probably because they could adapt the surrounding condition. Previous study Gerling et al. (1986) found that if host plants were cultivated continuously in time and space, the population of B. tabaci would increase and cause greater damage to host plants grown later in the planting season. In fact, outbreaks of $B$. tabaci in Brazil occurred under such circumstances (Kogan and Turnipseed, 1987). The distribution of immature whiteflies varied significantly among the leaf strata. The upper stratum harboured lower number of whitefly larvae. This part of brinjal plant consisted of young leaves, a preferred place for egg oviposition (Butler et al., 1983). Since only the larvae and pupae were counted in this study, the upper stratum consequently had lower number of whitefly larvae. The population on the upper stratum was highly exposed to the rain which might have a direct effect on the whitefly larvae, which could be brushed off from the under surfaces of the leaves. Furthermore, first and second nymphal stages of whitefly had higher mortality rate (Horowitz et al., 1984). A similar situation was also observed in another study carried out by Hassan (1996). He reported that, each species of whitefly in different agricultural ecosystems could exhibit different patterns of spatial distribution.

The distribution of the whitefly larvae was strongly dependent on the leaf strata during different cropping as the interaction between strata and cropping was different and highly significant. The population pattern of $B$. tabaci changed in the middle stratum. This indicates that the sampling of $B$. tabaci could be represented at the middle part of brinjal plants. According to Von Arx et al. (1984) in Sudan, about 50\% of the whitefly population lived on the main stem of cotton leaves (middle stratum) during the period of maximum population density. Ekbom and Xu, (1990) noted that the distribution of $B$. tabaci on plants was far from random, since the insects tend to select both particular plants and parts of the plant. For the sampling of immature stages, it has been difficult to estimate accurately the population density of $B$. tabaci. Population dynamics has traditionally sought to explain spatial distribution, one of the most important characteristics and ecological properties of insect species as the by-product of environmental heterogeneity and reproductive population growth act on random process of movement and mortality (Taylor, 1984). He also noted that field sampling was not complete and cannot be sustained without understanding the underlying spatial distribution. The earlier studies on the distribution of $B$. tabaci larvae on brinjal plants showed that the population of $B$. tabaci were aggregated on all plant strata except upper stratum. In the first cropping, whitefly larvae population was low at the upper stratum and was not aggregated. This could possibly be due to the field experiment located in a new area with very low whitefly infestation. However, in the second cropping the number of whitefly larvae was increased and an aggregated pattern was observed. The upper stratum, which mainly consisted of young leaves, provided a favourable place for whitefly adults to lay eggs confirming similar finding with the previous study carried out by McAuslane (1995). The main reason was that, the larvae emerged a week after the eggs have been oviposited on the under surfaces of the leaves, resulting in low number of $B$. tabaci larvae found in the upper stratum. When the new leaves had appeared, the secondary leaves reached their maturity and the level or stratum changed to the middle stratum. Furthermore, larval and pupal stages had longer life cycle, which was about 23.6 days at $25^{\circ} \mathrm{C}$ (Coudriet et al., 1985). Hence the larvae and pupae were mainly found at the middle stratum. Otherwise, the number of larvae and pupae were found to be lower at the lower stratum because most of the pupae had been emerged to adults. The physiological growth and development of brinjal plants took a longer duration the middle stratum than upper and lower strata. Some of the factors might influence in the spatial distribution probably due to cultural practices such as pruning the old leaves at the lower stratum which resulted in the number of larvae to be smaller in the lower stratum.

\section{Conclusion}

This study concludes that the total number of whitefly larvae pests was found to be most abundant at the middle stratum of the brinjal plants. The quantity of food source is one of the major factors that have attracted whitefly in the area. In fact, its flight ability enables them to search food quickly. Thus, this could encourage whitefly to reproduce in great numbers and subsequently cause severe infestation in the fields. There would be more serious damage to the field planted later in the next cropping, if the host plants were cultivated continuously in time and space of a same area.

\section{References}

Brown, J.K., and Nelson, M.R. (1986). Whitefly-borne Viruses of Melons and Lettuce in Arizona. Phytopathology 76: 236-239.

Butler Jr.G.D., Henneberry, T.J. and Clayton, T.E. (1983). Bemisia tabaci (Homoptera: Aleyrodidae): Development, oviposition, and longevity in relation to temperature. Annals of the Entomological Society of America 76. pp. 310-313. 
Coudriet, D.L., Prabhaker, N., Kishaba, A.N., and Meyerdirk, D.E. (1985). Variation in Developmental Rate on Different Hosts and Overwintering of the Sweetpotato Whitefly, Bemisia tabaci (Homoptera: Aleyrodidae). Environ. Ent. 14: 516-519.

Duffus, J.E. (1996). Whitefly-borne Viruses. In: Gerling, D., Mayer, M.T. (Eds.), Bemisia tabaci, 1995. Taxonomy, Biology, Damage, Control and Management. Intercept Limited, Andover, UK, pp: 255-263.

Ekbom, B.S. and Xu, R. (1990). Sampling and Spatial Patterns of Whiteflies in: Whiteflies: Their Bionomics, Pest Status and Management, D. Gerling (ed.). Intercept, Hants, United Kingdom. pp. 107-121.

Gerling, D., Horowitz, A.R., and Baumgaertner, J. (1986). Autecology of Bemisia tabaci. Agriculture, Ecosystems and Environment 17: 5-19.

Hassan, S.T.S. (1996). Population and Distribution Parameters of Athropods of Wet Paddy Ecosystem, and Their Fits to Distribution Models. Department of Biology, Universiti Pertanian Malaysia. Malays. Appl. Biol 25(2): 61-68.

Horowitz, A.R., Podoler, H., and Gerling, D. (1984). Life Table Analysis of the Tobaco Whitefly Bemisia tabaci (Gennadius) in Cotton Fields in Israel. Acta Ecological/Ecologia Applicata 5: 221-233.

Kogan, M., and Turnipseed, S.G. (1987). Ecology and Management of Soybean Arthropods. Annual Review of Entomology 32: 507-538.

Kohji, H., Erma, B., and Sri, W. (1993). Biological Characteristics and Forecasting Outbreaks of the Whitefly, Bemisia tabaci, a Vector of Virus Diseases in Soybean Fields. Food \& Fertilizer Technology Centre. 15 p.

McAuslane, H.J. (1995). Sweetpotato Whitefly B Biotype of Silverleaf Whitefly, Bemisia tabaci (Gennadius) or Bemisia argentifolii Bellows and Perring (Insecta: Homoptera: Aleyrodidae). Cooperative Extension Service, Institute of Food and Agricultural Sciences.

Sandra, D.S. and Ramon, C.L. (1987). SAS System for Elementary Statistical Analysis. SAS Institute Inc. 418 p.

Taylor, L. R. (1961). Aggregation, Variance, and the Mean. Nature 189: 732-5.

Taylor, L. R. (1984). Assessing and Interpreting the Spatial Distributions of Insects Population. Annu. Rev. Entomol. 29: 57-321.

Von Arx, R., Baumgärtner, J. and Delucchi, V. (1984). Sampling of Bemisia tabaci (Genn.) (Sternorhyncha:Aleyrodidae) in Sudanese Cotton Fields. Journal of Economic Entomology 77. pp. 1130-1136.
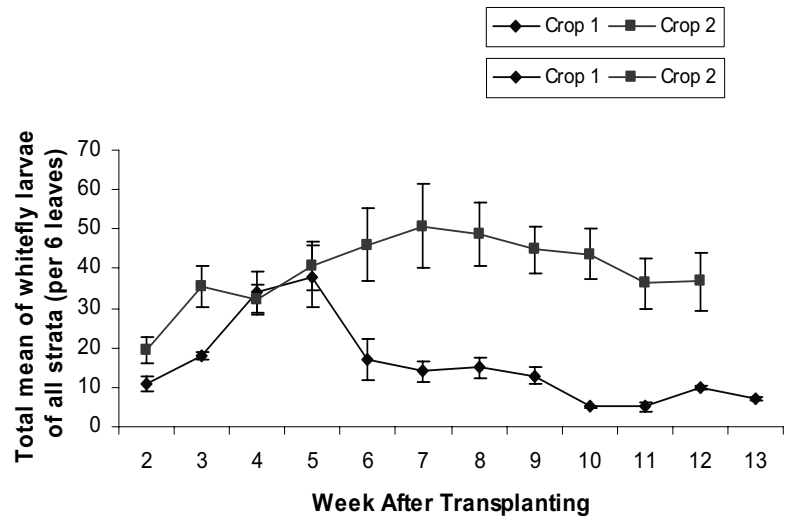

Figure 1. Distribution and abundance of whitefly larvae on each brinjal plant (total mean larvae in three leaf strata) in two cropping periods. 
Cropping Period 1

(a)

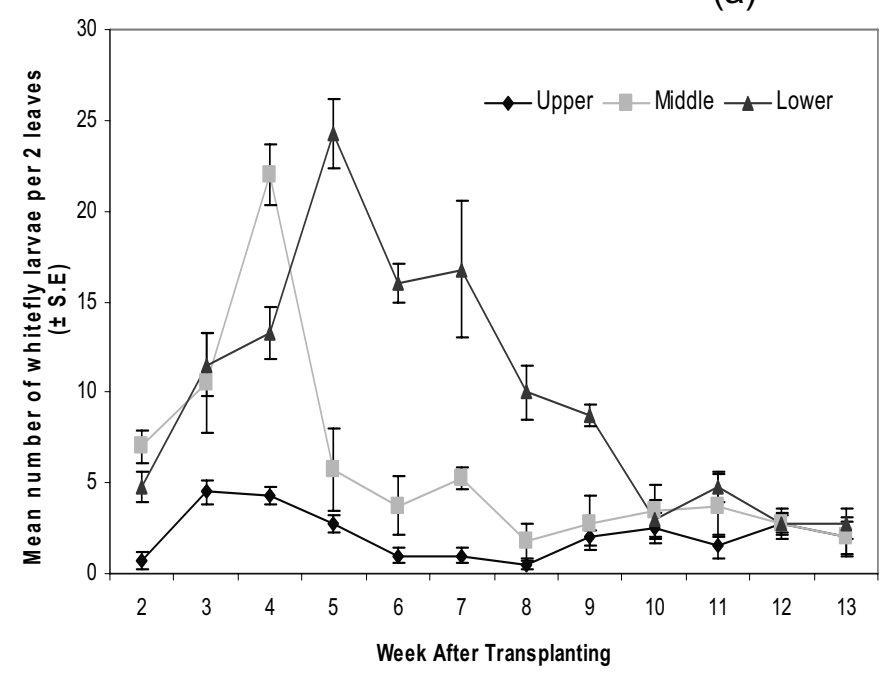

Cropping Period 2

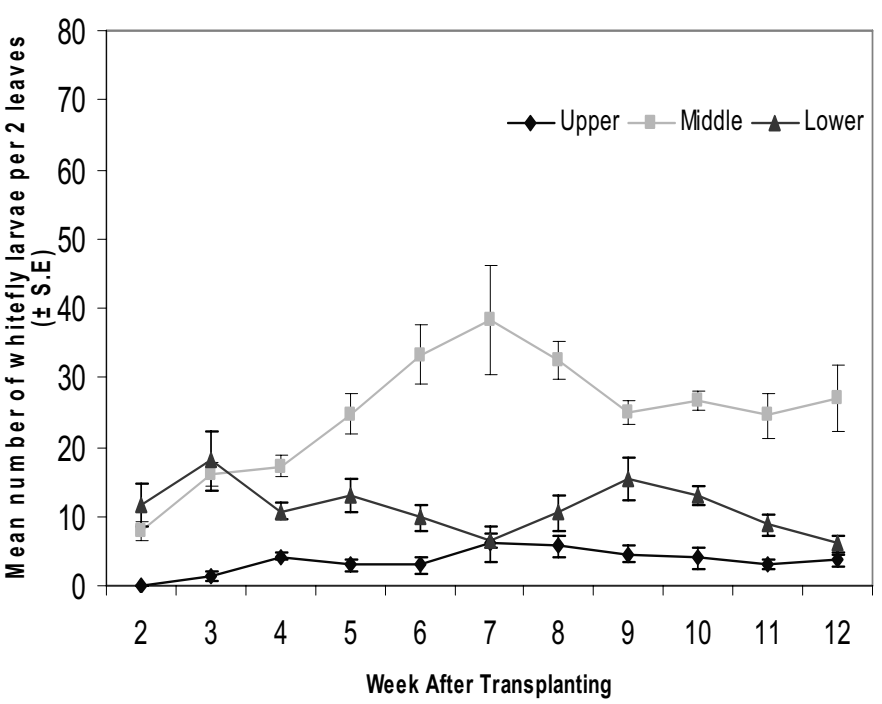

Figure 2. Mean number of whitefly larvae on upper, middle and lower strata of brinjal plant per 2 leaves (a) First cropping (b) Second cropping.

(a)

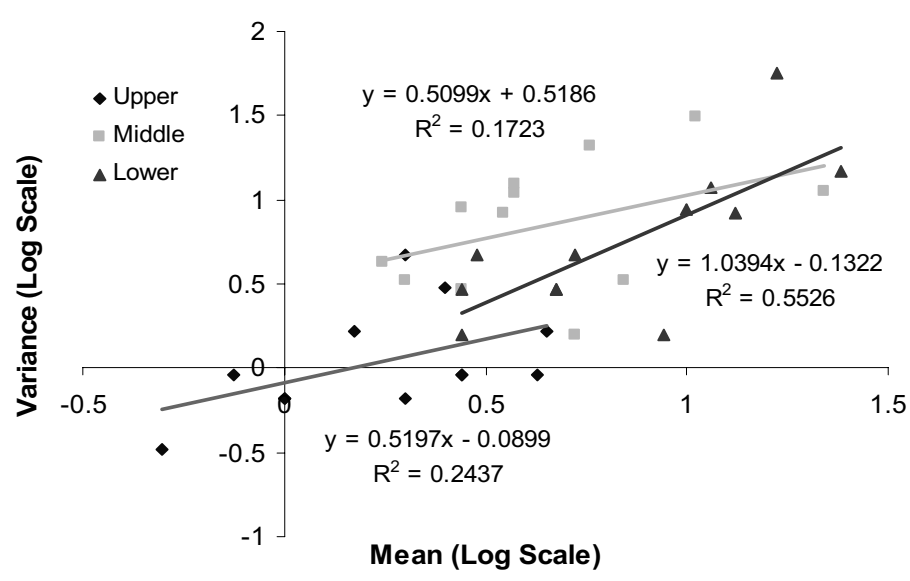

(b)

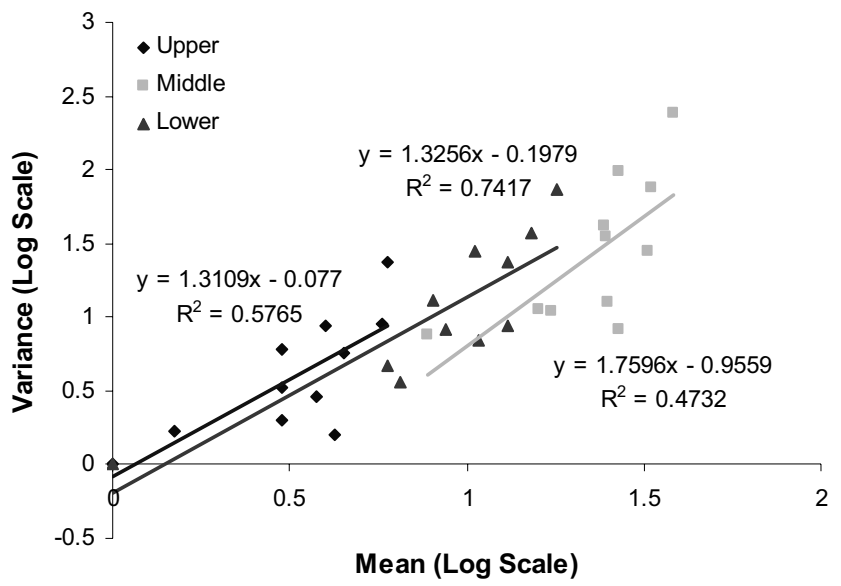

Figure 3. Spatial distribution of whitefly larvae on brinjal with Taylor's Power Law regressions
(a) First cropping
(b) Second cropping 